\title{
PENGARUH INOVASI, PENGAMBILAN RISIKO, PROAKTIF, OTONOMI DAN AGRESIVITAS BERSAING TERHADAP KINERJA UKM DI JAKARTA BARAT
}

\author{
Harry Wilson ${ }^{1}$, Ida Puspitowati \\ ${ }^{1}$ Program Studi Manajemen, Fakultas Ekonomi dan Bisnis, Universitas Tarumanagara \\ Email: harry.115150061@stu.untar.ac.id \\ ${ }^{2}$ Program Studi Manajemen, Fakultas Ekonomi dan Bisnis, Universitas Tarumanagara* \\ Email: idap@fe.untar.ac.id \\ *Penulis Korespondensi
}

Masuk : 04-02-2021, revisi: 10-02-2021, diterima untuk diterbitkan : 02-03-2021

\begin{abstract}
ABSTRAK
Tujuan penelitian ini untuk mengetahui dan menganalisis pengaruh inovasi, pengambilan risiko, proaktif, otonomi dan agresivitas bersaing terhadap kinerja UKM di Jakarta Barat. Metode penentuan sampel menggunakan metode non probability sampling dengan jenis purposive sampling. Metode pengumpulan data dengan menggunakan kuesioner yang di bagikan kepada 50 responden. Analisis data menggunakan analisis SEM PLS. Hasil analisis menyimpulkan bahwa terdapat pengaruh inovasi, pengambilan risiko, proaktif, otonomi dan agresivitas bersaing terhadap kinerja UKM di Jakata Barat.
\end{abstract}

Kata Kunci: inovasi, pengambilan risiko, proaktif, otonomi, agresivitas bersaing, kinerja

ABSTRACT

The purpose of this study was to determine and analyze the effect of innovativeness, risk-taking, pro-activeness, autonomy and competitive aggressiveness on the performance of SMEs in West Jakarta. The sampling method used non-probability sampling method with purposive sampling type. The data collection method used a questionnaire which was distributed to 50 respondents. Data analysis using SEM PLS analysis. The results of the analysis conclude that there is an effect of innovativeness, risk-taking, pro-activeness, autonomy and competitive aggressiveness on the performance of SMEs in West Jakarta.

Keywords: innovativeness, risk-taking, pro-activeness, autonomy, competitive aggressiveness, performance

\section{PENDAHULUAN}

\section{Latar Belakang}

Perkembangan perekonomian di Indonesia tidak dapat dilepaskan dari keberadaan Usaha Kecil dan Menengah (UKM). Mayoritas wilayah di Indonesia struktur perekonomiannya ditopang oleh UKM yang menganut sistem ekonomi kerakyatan dan usaha kerakyatan (Hamel dan Wijaya, 2020). Jenis usaha ini telah terbukti tahan terhadap segala gangguan, termasuk mampu bertahan pada parahnya krisis ekonomi yang melanda Indonesia pada era tahun 1998 (Hamel dan Wijaya, 2020). Usaha pada kategori ini memiliki peranan yang sangat penting bagi peningkatan perekonomian masyarakat dan negara. Sektor UKM menciptakan lapangan pekerjaan lebih cepat dibandingkan sektor usaha lain, dan mereka juga cukup terdiversifikasi dan memberikan kontribusi penting dalam ekspor dan perdagangan (Kanaidi, 2014, h. 101). Kinerja usaha menjadi penting untuk dibicarakan karena menyangkut keberadaan dan keberlangsungan usaha dimasa yang akan datang. Tanpa adanya kinerja usaha, maka UKM yang selama ini dijalankan berarti dianggap tidak mampu memberikan kontribusi yang menguntungkan bagi pengelola dan orang lain yang ikut terlibat didalammya. 
Kinerja usaha merupakan salah satu ukuran prestasi dari sebuah usaha yang didapatkan melalui aktifitas produksi dan pemasaran secara keseluruhan yang berasal dari organisasi bisnis. Kinerja usaha dapat dipandang sebagai sebuah konsep yang digunakan dalam mengukur sampai dimana prestasi pasar yang telah dicapai oleh suatu produk yang dihasilkan organisasi bisnis. Ferdinand (2010) mengungkapkan bahwa kinerja usaha merupakan salah satu faktor yang seringkali digunakan untuk mengukur dampak dari strategi usaha yang telah diterapkan perusahaan.

Menurut Lumpkin dan Dess (1996, dalam Arshad dkk., 2014) keberhasilan wirausaha tergantung pada pribadi atau motivasi pribadi. salah satu aspek yang penting dalam motivasi pribadi dalam berwirausaha adalah orientasi kewirausahaan. Orientasi kewirausahaan berhubungan dengan cara berwirausaha dalam hal ini seperti metode yang dipakai, kebiasaan dan gaya pengambilan keputusan yang digunakan dalam berwirausaha (Lee dan Peterson, 2000). Orientasi kewirausahaan terdiri atas innovativeness, risk taking, autonomy,pro-activiness dan competitive aggressiveness (Lee dan Peterson, 2000).

Penelitian yang dilakukan Arshad, dkk (2014) menemukan bahwa inovasi berpengaruh terhadap kinerja usaha. Inovasi dapat dipertimbangkan pada produk atau tingkat teknologi (Yang, 2008). Seorang wirausaha yang menjalankan usaha UKM, harus bersikap proaktif jika usaha yang dijalankan ingin bertahan dalam kondisi apapun. Wirausaha yang bersikap proaktif akan mampu membuat keputusan secara bijak dan bertanggung jawab atas keputusan tersebut, tanpa terpengaruh suasana hati atau keadaan. Proaktif mengacu pada proses mengantisipasi dan bertindak atas kebutuhan masa depan dengan mencari peluang-peluang baru (Handayani dkk., 2014, h. 13).

Selain itu, menurut Hapsari dan Setiawan (2019) faktor yang mempengaruhi kinerja usaha adalah berani mengambil risiko. Keberanian mengambil resiko adalah keberanian manajer untuk membuat keputusan besar dan komitmen yang beresiko dimana memiliki kesempatan kegagalan yang berharga (Handayani dkk, 2016). Risiko dapat berupa tingkat pribadi, sosial atau fisiologis.

Menurut Guatam (2016) faktor yang mempengaruhi kinerja usaha adalah autonomy. Otonomi merupakan kegiatan independen individual (mandiri) atau tim dalam menjabarkan ide-ide atau visi, membuat keputusan dan mengambil tindakan yang bertujuan untuk memajukan konsep bisnis dan membawanya pada penyelesaian. Dalam penelitian yang dilakukan oleh Arshad dkk (2014) menyatakan bahwa autonomy berpengaruh terhadap kinerja usaha. Seorang wirausaha juga membutuhkan nasehat atau masukan dari orang lain untuk mengembangkan usahanya. Selain inovasi, proaktif, keberanian mengambil risiko dan autonomi, agresivitas bersaing merupakan faktor yang dapat mempengaruhi kinerja usaha (Gautam, 2016). Agresivitas bersaing mengacu pada kecenderungan perusahaan untuk secara langsung dan intens menghadapi pesaingnya untuk memasuki atau untuk memperbaiki posisi, yaitu untuk lebih mengungguli rival industri di pasar dan untuk mencapai keunggulan kompetitif. Tujuan penelitian ini adalah untuk menguji pengaruh Inovasi, Pengambilan Risiko, Proaktif, Otonomi dan Agresivitas Bersaing terhadap Kinerja UKM di Jakarta Barat.

\section{Kajian teori}

Fontana (2011) mendefinisikan inovasi sebagai proses pengenalan produk atau sistem baru yang membawa kesuksesan ekonomi bagi perusahaan dan kesuksesan sosial bagi konsumen serta komunitas atau lingkungan yang lebih luas. Dari pengertian tersebut dapat dijelaskan bahwa Inovasi merupakan salah satu faktor penting dalam kesuksesan suatu perusahaan, melalui inovasi yang diciptakan guna memuaskan pelanggan. 
Pengambilan risiko menurut Handayani, dkk. (2014) adalah keberanian untuk membuat keputusan besar dan komitmen yang berisiko dimana memiliki kesempatan kegagalan yang berharga. Seorang wirausaha harus berani mengambil keputusan, walaupun dengan resiko kegagalan.

Menurut Kreiser (2015), proaktif dapat diartikan sebagai pengambilan tindakan atau inisiatif untuk melakukan sesuatu untuk mencapai tujuan yang telah ditetapkan. Seseorang dengan proaktivitas tinggi, mampu mengidentifikasi kesempatan dan mengambil tindakan yang tepat untuk memanfaatkan kesempatan tersebut, menampakkan inisiatif dan mempertahankannya, sampai adanya perubahan yang berharga untuknya.

Menurut Hatta (2014), otonomi adalah keleluasaan atau kebebasan individu dalam berfikir dan bertindak kreatif dalam mengatasi berbagai persoalan atau dalam mengoptimalkan peluang baru yang menarik di pasar. Seorang wirausaha harus memiliki kemampuan berpikir dan kreativitas untuk memanfaatkan peluang yang ada tanpa tergantung dari orang lain.

Menurut Vij dan Vedi (2012, h. 25) "Competitive aggressiveness refers to the propensity of a firm to directly and intensely challenge its competitors to achieve entry or improve its position, i.e. to outperform rivals in its market domain" Agresivitas bersaing mengacu pada kecenderungan perusahaan untuk secara langsung dan intens menantang para pesaingnya untuk masuk atau meningkatkan posisinya, yaitu mengungguli pesaing dalam domain pasarnya. Berdasarkan pengertian tersebut agresivitas bersaing dapat diartikan sebagai intensitas keinginan untuk mengalahkan lawan bisnis.

Menurut Sampurno (2010) Kinerja adalah akumulasi hasil akhir dari seluruh aktivitas dan proses kerja dariperusahaan. Atau kinerja adalah suatu tampilan keadaan secara utuh atas perusahaan selama periode waktu tertentu, merupakan hasil atau prestasi yang dipengaruhi oleh kegiatan operasional perusahaan dalam memanfaatkan sumber-sumber daya yang dimiliki. Dari pengertian tersebut kinerja merupakan seluruh hasil yang didapat dengan memanaatkan sumber daya yang dimiliki dalam periode waktu tertentu.

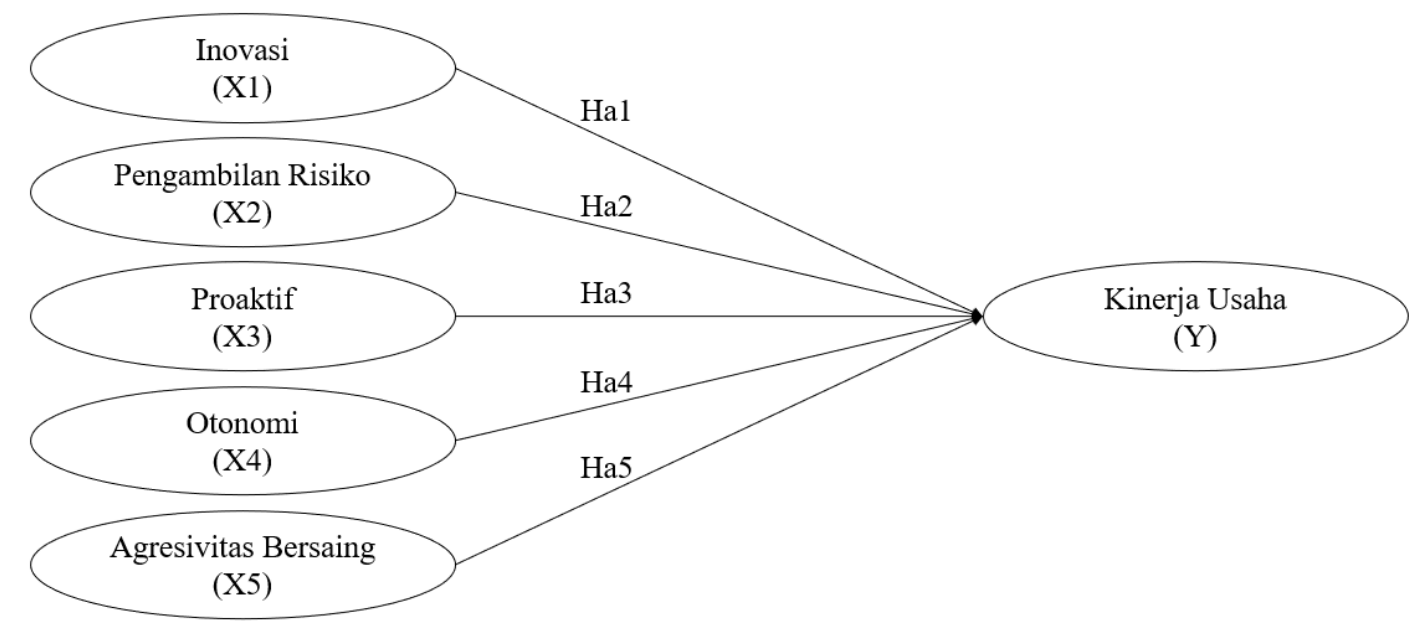

Gambar 1. Model penelitian

Berdasarkan ulasan diatas maka hipotesis sebagai berikut:

Ha1: Terdapat pengaruh signifikan inovasi terhadap kinerja usaha

Ha2: Terdapat pengaruh signifikan pengambilan risiko terhadap kinerja usaha 
Ha3: Terdapat pengaruh signifikan proaktif terhadap kinerja usaha

Ha4: Terdapat pengaruh signifikan Otonomi terhadap kinerja usaha

Ha5: Terdapat pengaruh signifikan Agresivitas bersaing terhadap kinerja usaha

\section{METODE PENELITIAN}

Penelitian ini merupakan penelitian deskriptif, yaitu penelitian dengan cara mengumpulkan data dari sebuah sampel dengan tujuan untuk mengetahui karakteristik dari suatu populasi (Sekaran \& Bougie, 2016). Pendekatan yang digunakan dalam penelitian ini adalah pendekatan cross sectional. Populasi penelitian ini adalah seluruh pelaku UKM yang berada di Kecamatan Cengkareng Jakarta Barat. Pengambilan sampel diambil dengan menggunakan metode jenis purposive sampling, karena didalam menentukan sampel ada pertimbangan-pertimbangan tertentu yaitu sampel haruslah pengusaha UKM yang masih beroperasi saat pandemi. Pengambilan sampel dilakukan di wilayah Kecamatan Cengkareng, Jakarta Barat, dengan jumlah sampel sebanyak 50 responden

Data dianalisis menggunakan PLS-SEM dimana data diolah dengan program software SmartPLS 3. Pertama, pengolahan dilakukan pada outer model untuk menguji validitas dan reliabilitas.

Pengolahan data dilakukan pada inner model untuk menguji hipotesis yang telah dihasilkan. Sebelum pengujian hipotesis, pertama dilakukan pengujian hubungan antar konstruk dengan melihat nilai $\mathrm{R}$-square $\left(\mathrm{R}^{2}\right)$, uji $\mathrm{Q}$-square $\left(\mathrm{Q}^{2}\right)$ dan nilai GoF (Goodness of Fit). Selanjutnya pengujian hipotesis, untuk melihat pengaruh yang terjadi lihat (positif/ negatif) dari coefficient yang dihasilkan, dan menggunakan $t$-statistics > 1,645 (hipotesis tidak ditolak) dan p-values < 0,05 (hipotesis signifikan) (Ghozali, 2014:50).

\section{HASIL DAN PEMBAHASAN \\ Hasil Uji Statistik \\ Hasil Uji Validitas}

Pada hasil validitas konvergen, didapatkan semua angka $>0,7$ pada nilai outer loadings untuk setiap pernyataannya, dan didapatkan semua angka > 0,5 pada nilai Average Variance Extracted (AVE) maka pernyataan yang digunakan sudah valid secara validitas konvergen. Selain itu, pada hasil validitas diskriminan, peneliti menggunakan nilai Cross Loadings dimana nilai korelasi antara pernyataan terhadap variabel nya sendiri harus lebih besar daripada pernyataan terhadap variabel lainnya. Berdasarkan hasil kalkulasi SmartPLS 3, didapatkan semua angka pada pernyataan terhadap variabel-nya sendiri lebih besar dibandingkan terhadap variabel lainnya maka pernyataan sudah valid secara validitas diskriminan.

\section{Hasil Uji Reliabilitas}

Tabel 1. Hasil Uji Reliabilitas
\begin{tabular}{|l|c|c|}
\hline \multicolumn{1}{|c|}{ Composite Reliability } & Cronbach's Alpha \\
\hline Inovasi & 0,918 & 0,880 \\
\hline Pengambilan Risiko & 0,895 & 0,844 \\
\hline Proaktif & 0,925 & 0,892 \\
\hline Otonomi & 0,948 & 0,931 \\
\hline Agresivitas Bersaing & 0,878 & 0,814 \\
\hline Kinerja Usaha & 0,931 & 0,911 \\
\hline
\end{tabular}

Pada hasil reliabilitas, maka berdasarkan hasil yang dikalkulasi oleh program SmartPLS 3, didapatkan semua angka pada nilai Cronbach's Alpha untuk setiap variabel adalah > 0,7 dan pada nilai composite reliability didapatkan semua angka untuk setiap variabel adalah > 0,7. 
Maka pernyataan dalam variabel yang digunakan dalam penelitian ini sudah reliabel berdasarkan kedua nilai reliabilitas, yakni Cronbach's Alpha dan composite reliability.

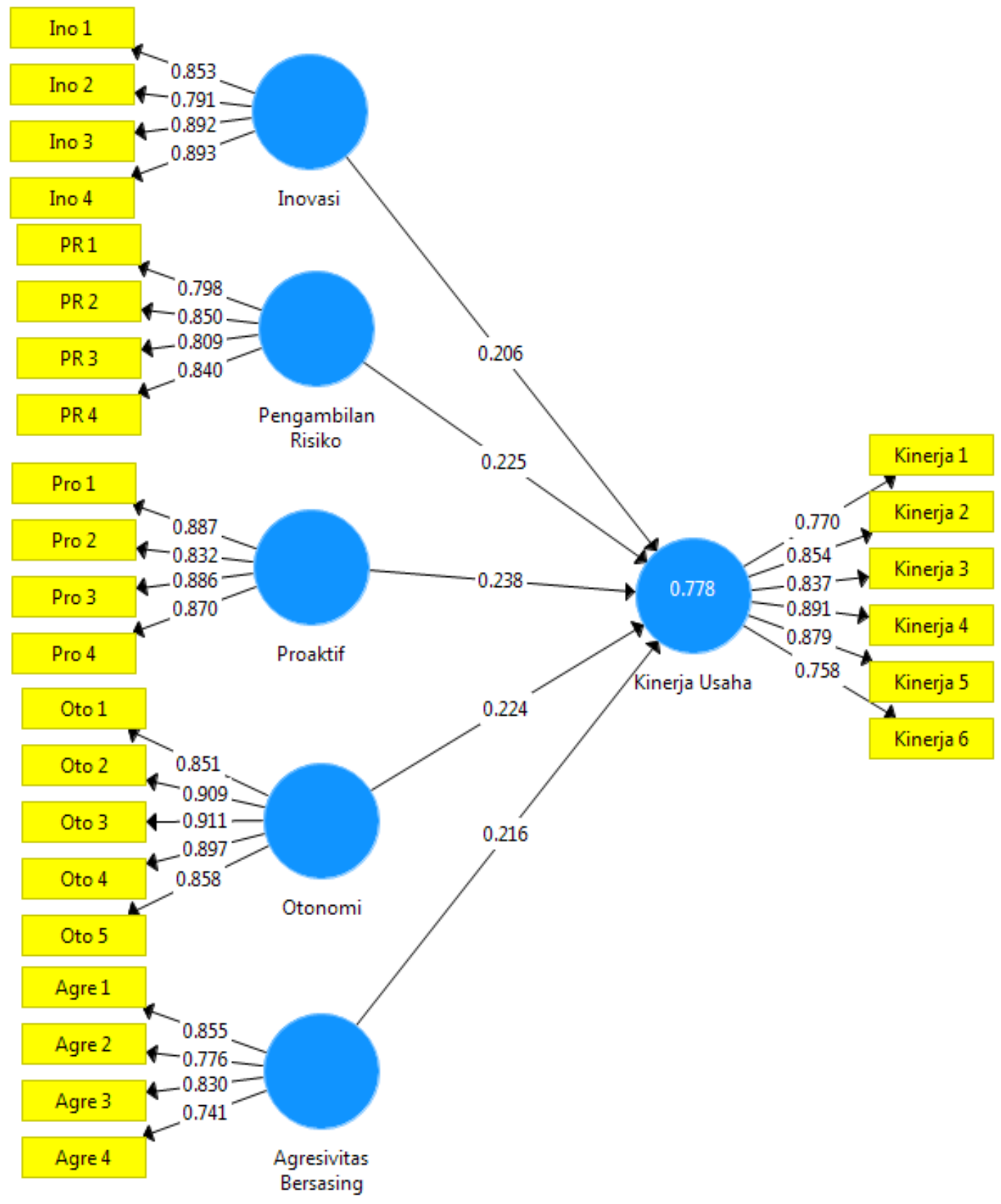

Gambar 2. Diagram loading factors

\section{Hasil Uji R-Square ( $\left.\mathbf{R}^{2}\right)$, f-square dan GoF (Goodness of Fit)}

Tabel 2. Output R-Square

Sumber: Hasil Pengolahan Data SmartPLS (PLS Algorithm)

\begin{tabular}{|l|c|}
\hline & $R$-Square \\
\hline Kinerja Usaha & 0.753 \\
\hline
\end{tabular}

Berdasarkan hasil dari pengujian koefisien determinasi yang telah ditampilkan pada tabel di atas, maka nilai $R$-Square adalah sebesar 0,753 , artinya sebesar $75.3 \%$ variasi kinerja usaha dapat 
dijelaskan oleh variasi Inovasi, Pengambilan Risiko, Proaktif, Otonomi dan Agresivitas Bersaing. Sisanya sebesar $24,7 \%$ dijelaskan oleh variabel lain

Tabel 3. Output f-Square

Sumber: Hasil Pengolahan Data SmartPLS (PLS Algorithm)

\begin{tabular}{|l|c|}
\hline \multicolumn{1}{|c|}{ Variabel } & $f$-Square \\
\hline Inovasi $\rightarrow$ Kinerja Usaha & 0,080 \\
\hline Pengambilan Risiko $\rightarrow$ Kinerja Usaha & 0,117 \\
\hline Proaktif $\rightarrow$ Kinerja Usaha & 0,135 \\
\hline Otonomi $\rightarrow$ Kinerja Usaha & 0,147 \\
\hline Agresivitas Bersaing $\rightarrow$ Kinerja Usaha & 0,093 \\
\hline
\end{tabular}

Pembagian kategori pada $\mathrm{f}^{2}$ terbagi menjadi tiga, yaitu 0,02 merupakan pengaruh lemah, 0,15 merupakan pengaruh sedang, dan 0,35 merupakan pengaruh kuat. Dari tabel di atas diketahui bahwa:

a. Variabel inovasi memiliki pengaruh lemah dalam model struktural, yaitu sebesar 0,080

b. Variabel pengambilan risiko memiliki pengaruh lemah dalam model structural, yaitu sebesar 0,117

c. Variabel proaktif memiliki pengaruh lemah dalam model struktural, yaitu sebesar 0,135

d. Variabel otonomi memiliki pengaruh lemah dalam model struktural, yaitu sebesar 0,147

e. Variabel agresivitas bersaing memiliki pengaruh lemah dalam model struktural, yaitu sebesar 0,093

\section{Hasil Pengujian Goodness of Fit (GoF)}

Berdasarkan hasil dari perhitungan Goodness of Fit $(\mathrm{GoF})$ diatas, maka dapat disimpulkan bahwa model yang dapat digunakan dalam penelitian ini kecocokan model penelitian yang tergolong besar dengan nilai 0,746 .

\section{Hasil Uji Hipotesis}

Tabel 4. Hasil Uji Hipotesis (Bootstrapping)

\begin{tabular}{|l|c|c|c|}
\hline & Original Sample (O) & $\begin{array}{c}t \text {-statistics } \\
(\text { JO/STDEV })\end{array}$ & $p$-value \\
\hline Inovasi $\rightarrow$ Kinerja Usaha & 0.206 & 2.222 & 0.027 \\
\hline Pengambilan Risiko $\rightarrow$ Kinerja Usaha & 0.225 & 2.077 & 0.038 \\
\hline Proaktif $\rightarrow$ Kinerja Usaha & 0.238 & 2.314 & 0.021 \\
\hline Otonomi $\rightarrow$ Kinerja Usaha & 0.224 & 2.505 & 0.013 \\
\hline Agresivitas Bersaing $\rightarrow$ Kinerja Usaha & 0.216 & 2.130 & 0.034 \\
\hline
\end{tabular}

Berdasarkan hasil dari path coefficients yang ditampilkan tabel diatas, maka dapat diperoleh persamaan dalam penelitian ini yaitu kinerja usaha= $0,206 \times 1+0,225 \times 2+0,238 X 3+0,224 X 4+0,216 \times 5$, dimana pengaruh variabel inovasi, variabel pengambilan risiko, variabel proaktif, variabel otonomi dan variabel agresivitas bersaing terhadap kinerja usaha mempunyai pengaruh yang positif.

Berikut merupakan diagram model dari hasi perhitungan bootstrapping pada SmartPLS: 


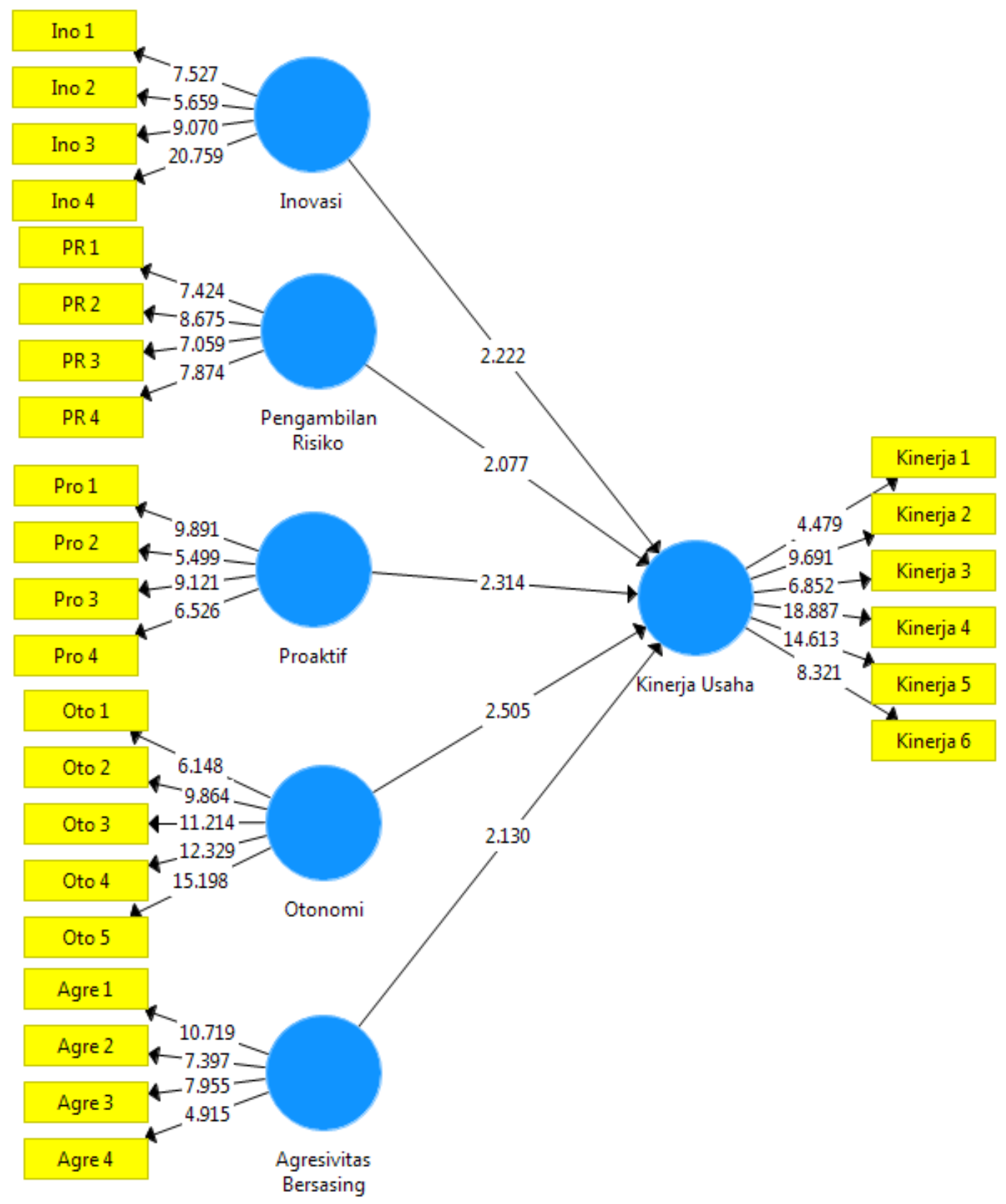

Gambar 3. Hasil perhitungan bootstrapping

Sumber: Olah data SmartPLS 3.0

\section{Diskusi}

Hipotesis yang pertama menunjukkan bahwa variabel inovasi terbukti berpengaruh secara signifikan terhadap kinerja Hasil ini sesuai dengan penelitian Arshad dkk., (2014) serta penelitian. Inovasi merupakan komponen yang tak terpisahkan dari strategi perusahaan untuk menerapkan proses manufaktur yang lebih produktif, tampil lebih baik di pasar, mencari reputasi positif dan untuk mendapatkan keunggulan yang kompetitif. Inovasi memberikan perusahaan sebuah orientasi strategis untuk mengatasi masalah yang dihadapi perusahaan oleh karena itu semakin baik inovasi maka semakin tinggi tingkat kesuksesan bisnis.

Hipotesis kedua menunjukkan bahwa variabel pengambilan risiko memiliki nilai $\mathrm{t}$-statistik sebesar 2,077 yang berarti lebih besar dari 1,96 dan p-values sebesar 0,038 yang berarti lebih 
kecil dari 0,05. Sehingga dapat disimpulkan bahwa pengambilan risiko memiliki pengaruh yang signifikan terhadap kinerja usaha. Hasil ini sesuai dengan penelitian Hatta (2014), Arshad, dkk., (2014) serta penelitian Hapsari dan Setiawan (2019) menyimpulkan bahwa kecenderungan mengambil risiko berpengaruh terhadap kinerja usaha. Dalam berwirausaha diperlukan keberanian untuk menghadapi risiko. Semakin besar risiko yang dihadapi, maka semakin besar pula kemungkinan dan kesempatan untuk meraih keuntungan yang lebih besar, bukan hanya keuntungan pada arti yang sesungguhnya yaitu uang atau investasi, tetapi juga keuntungan dalam menjalin hubungan baik sebagai relasi dengan banyak pihak.Umumnya resiko yang tinggi akan menghasilkan pengembalian yang tinggi sehingga seringkali pengambilan resiko dihubungkan dengan kesuksesan bisnis.

Hipotesis ketiga menunjukkan bahwa variabel proaktif memiliki nilai t-statistik sebesar 2,314 yang berarti lebih besar dari 1,96 dan p-values sebesar 0,021 yang berarti lebih kecil dari 0,05. Sehingga dapat disimpulkan bahwa proaktif memiliki pengaruh yang signifikan terhadap kinerja usaha. Hasil ini sesuai dengan penelitian Hapsari dan Setiawan (2019) dan Arshad dkk (2014) yang menyatakan bahwa proaktif berpengaruh terhadap kinerja usaha. Perilaku proaktif sebagai upaya mengambil inisiatif dalam meningkatkan ide dan kreativitas-kreativitas baru mengubah status quo dibanding hanya bertindak pasif dalam menghadapi kondisi saat ini.Sikap proaktif harus dimiliki oleh seorang wirausaha karena dengan sikap proaktif dapat memajukan usaha yang dijalankannya. Sikap proaktif juga dapat menjadikan seseorang mampu menangkap peluang yang ada, memiliki visi yang jelas kedepan, selalu aktif dan memikirkan apa yang dapat dilakukan untuk meningkatkan usaha yang dijalaninya. Semakin proaktif sifat pengusaha maka semakin sukses bisnis yang dikelolanya.

Hipotesis keempat menunjukkan bahwa variabel otonomi memiliki nilai t-statistik sebesar 2,505 yang berarti lebih besar dari 1,96 dan p-values sebesar 0,013 yang berarti lebih kecil dari 0,05. Sehingga dapat disimpulkan bahwa otonomi memiliki pengaruh yang signifikan terhadap kinerja usaha. Hasil ini sesuai dengan penelitian Gautam (2016) dan Hatta (2014) menyatakan bahwa otonomi berpengaruh positif terhadap kinerja usaha. Otonomi adalah karakteristik dari seorang wirausahawan yang dapat mengandalkan dirinya sendiri dan percaya diri terhadap kemampuannya sendiri sebagai seorang pebisnis yang baik. Kunci keberhasilan dalam bisnis adalah memahami diri sendiri dan bertindak mandiri, oleh sebab itu wirausaha yang sukses adalah wirausaha yang mandiri dan percaya diri.

Hipotesis kelima menunjukkan bahwa variabel agresivitas bersaing memiliki nilai t-statistik sebesar 2,130 yang berarti lebih besar dari 1,96 dan p-values sebesar 0,034 yang berarti lebih kecil dari 0,05. Sehingga dapat disimpulkan bahwa agresivitas bersaing memiliki pengaruh yang signifikan terhadap kinerja usaha. Hasil ini sesuai dengan penelitian Arshad dkk (2014) dan Gautam (2016) menyatakan bahwa agresivitas bersaing berpengaruh terhadap kinerja usaha. Agresivitas bersaing mengacu pada kecenderungan perusahaan untuk secara langsung dan intens menantang pesaingnya untuk mencapai masuk atau memperbaiki posisi, yaitu mengungguli rival industri di pasar. Sikap agresivitas bersaing yang kuat memungkinkan perusahaan untuk menjadi pemain yang menentukan dalam bidang usahanya dibanding pesaing dan bertindak kuat untuk melindungi atau memajukan usahanya.

\section{KESIMPULAN DAN SARAN}

Berdasarkan analisis dan pembahasan, maka dapat disimpulkan bahwa inovasi, pengambilan risiko, proaktif, otonomi dan agresivitas bersaing berpengaruh signifikan terhadap kinerja usaha UKM di Jakarta Barat. 
Dari hasil penelitian tersebut, maka beberapa saran yang dapat diberikan adalah: bagi para pengusaha diharapkan selalu berinovasi dan berani mengambil risiko atau meningkatkan kualitas produk yang dibuatnya dengan mengikuti trend jaman sekarang sehingga akan memberikankepuasan lebih tinggi bagi konsumen yang akan membeli. Bagi para pengusaha hendaknya proaktif untuk mencari peluang usaha dan berinsiatif utuk memanfaatkan peluang yang ada sehingga dapat meningkatkan kinera usahanya. Pengusaha agar dapat melepas diri dari ketergantungan pada pihak lain sehingga lebih mudah mengatur usaha mengenali lingkungan dan menyusun strategi bersaing yang tepat.

\section{REFERENSI}

Arshad, Azlin Shafinaz, Amran Rasli, Afiza Azura Arshad, dan Zahariah Mohd Zain (2014) The Impact of Entrepreneurial Orientation on Business Performance: A Study of Technologybased SMEs in Malaysia. Procedia - Social and Behavioral Sciences. 1 (3): 46 - 53

Fontana, Avanti. (2011). Innovate We Can!. Bekasi : Cipta Inovasi Sejahtera

Gautam Prabin Raj (2016) Entrepreneurial Orientation And Business Performance Of Handicraft Industry: A Study Of Nepalese Handicraft Enterprises International Journal of Small Business and Entrepreneurship Research. 4 (2): 48-63.

Ghozali, Imam. (2014). Structural Equation Modeling, Metode Alternatif dengan Partial Least Square (PLS). Edisi 4. Semarang: Badan Penerbit Universitas Diponegoro

Hamel, Calvin dan Wijaya, Andi (2020) Pengaruh Orientasi Kewirausahaan dan Orientasi Pasar terhadap Kinerja Usaha UKM Di Jakarta Barat. Jurnal Manajerial dan Kewirausahaan. 2 (4): 863-872

Handayani, Naniek Utami, Haryo Santoso dan Yengky Imam Susanto (2014) Faktor-Faktor Yang Berpengaruh Terhadap Kewirausahaan Di Klaster Industri Mebel Kabupaten Blora.

Journal of Industrial Engineering Management. 9 (1): 1-10

Hapsari, Nurmalita Rhizky dan Setiawan, Achma Hendra (2019) Analisis Orientasi Kewirausahaan Terhadap Kinerja Usaha Industri Kreatif Bidang Kerajinan Di Kota Semarang. Diponegoro Journal Of Economics. 1 (1): 47-54.

Hatta, Iha Haryani (2014) Analisis Pengaruh Inovasi, Pengambilan Resiko, Otonomi, Dan Reaksi Proaktif Terhadap Kapabilitas Pemasaran Ukm Kuliner Daerah Di Jabodetabek. Jurnal Manajemen Pemasaran. 8 (2): 90-96

Kanaidi. (2014). Pengaruh Orientasi Pasar, Orientasi Enterpreneur dan Inovasi Organisasi Terhadap Kinerja Usaha. Strategic Management Journal. 14 (2): 95-153

Kreiser P; (2015). Correlates of Entrepreneurship: The Impact of National Culture on Risktaking Proactiveness in SMEs. Academy of Management Journal, 51(1): 97-111.

Lee, S. M., and Peterson., S. J. (2000). Culture, Entrepreneurial Orientation, and Global Competitiveness, Journal of World Business. 3 (5): 1-14

Sampurno (2010). Manajemen Strategik: Menciptakan Keunggulan Bersaing yang Berkelanjutan. Yogyakarta: Gajah Mada University Press

Sekaran, Uma dan Bougie, Roger. (2016). Research Methods For Business: A Skill Building Approach, 7th Edition. New Jersey: Wiley

Vij, S. And Bedi, H. S. (2012). Relationship between Entrepreneurial Orientation and Business Performance. A Review of Literature. IUP Journal of Business Strategy. 9 (3), 17-31.

Yang, J. T. (2008). Individual attitudes and organisational knowledge sharing. Tourism Management. 29 (2): 345-353. 